Article

\title{
Study on the Timely Adjustment of the Grazing Prohibition Policy: Ban or Lift? Empirical Research from Local Government Managers
}

\author{
Lihua Zhou ${ }^{1}$, Ya Wang ${ }^{2, *(1)}$ and Guojing Yang ${ }^{3}$ \\ 1 Institutes of Science and Development, Chinese Academy of Sciences, Beijing 100190, China; \\ lhzhou@casisd.cn \\ 2 Key Laboratory of Desert and Desertification, Northwest Institute of Eco-Environment and Resources, \\ Chinese Academy of Sciences, Lanzhou 730000, China \\ 3 Key Laboratory of Ecohydrology of Inland River Basin, Northwest Institute of Eco-Environment and \\ Resources, Chinese Academy of Sciences, Lanzhou 730000, China; yangguojing@lzb.ac.cn \\ * Correspondence: wangya2014@lzb.ac.cn; Tel.: +86-0931-496-7550
}

Received: 13 November 2018; Accepted: 12 December 2018; Published: 19 December 2018

\begin{abstract}
As national policy implementers and regional development planners, local government managers have a clearer, more objective and comprehensive understanding of ecological changes than herdsmen. Thus, they have a significant impact on the sustainable development of grassland resources and agricultural and pastoral areas. In this paper, grassland ecological change and related factors in different stages were investigated by means of questionnaires and structured interviews, and the adjustment strategies of grazing prohibition policy were studied. The perception of local government managers was that there was an improvement in grassland ecology, coverage, quality, yield, and in species richness in the early grazing prohibition period. There was, furthermore, an obvious improvement in the intermediate stage and a significant improvement with some degradation in its current stage. The grazing prohibition policy urgently needs to be adjusted according to the management pattern and to the limited time and space. It is necessary to improve the standard of ecological compensation and bolster herdsmen livelihoods, diversification, and non-agriculturalization. Based on the non-equilibrium theory and polycentric governance, the multi-central grassland governance and control system should be created in future.
\end{abstract}

Keywords: grassland ecology; grazing prohibition policy; environment perception; local government managers; Yanchi County

\section{Introduction}

The agro-pastoral ecotone in northern China is a unique geographical unit. It is an ecological transition and blending zone between eastern agricultural areas and western grassland pastures [1,2] This ecotone is also an important agricultural and livestock production area and ecological protection barrier. The natural ecosystem in this area is sensitive to external interference, and its ecological process is distinctive. From the late 1950s to the end of the 1990s, there had been a series of ecological problems, such as land desertification, soil erosion, and sandstorms [2], due to the natural ecological vulnerability (drought, wind, freezing, snow) and irrational human activities (grassland cultivating and overgrazing) in historical periods. This situation has affected the development of the local socio-economies, and even seriously threatened the eastern agricultural regions and national ecological security.

How to effectively manage and prevent the emergence of the "tragedy of commons"? Economists had put forward two kinds of management methods: Government control and 
privatization of property rights. In China, the improvement of the grassland environment would be realized through the compulsory action of the national policy system. In response to the situation of the grassland degradation and desertification expansion in the agro-pastoral ecotone in northern China, a comprehensive grazing prohibition policy (GPP) was implemented in 2003. This policy is an important measure for the project of returning grazing to grass that was implemented in 11 western provinces including Inner Mongolia, and the Ningxia and Gansu provinces. The main component of the GPP is the exchange of subsidies, including forages, feed grain, and subsidies granted for policy considerations, through the containment of degraded grassland and the prohibition of grazing. The government subsidized feed grain per year for grazing prohibition by $82.50 \mathrm{~kg} / \mathrm{ha}$ since 2003 . After 2005, in some severely degraded grasslands, the subsidy form changed from feed grain type to cash type, and the reseeding grass seed subsidy was $\$ 23.10 /$ ha [3]. During 2011-2015, the subsidy increased by $\$ 13.85 /$ ha and a $\$ 76.90$ production subsidy for each household was granted. This has increased by $\$ 17.31 /$ ha per year since 2016 . In the past 15 years, grassland ecology has recovered remarkably and the local socio-economic benefits are significant. Meanwhile, after more than a 10-year process of the GPP, new problems have gradually emerged. Against the background of vigorously promoting the construction of ecological civilization and green development, the following is the key to ensure the sustainable restoration of grassland ecological: The detailed analysis and scientific evaluation of the GPP, and the consideration of future development policy.

Human cognition and the awakening of eco-environmental changes directly determined the style and level of people's production and life and even indirectly affected the sustainable development of the regional eco-environment. The research on environmental change cognition of herdsmen is a hot topic in recent years, and results are abundant. The characteristics of herdsmen's perception of the environment are mainly manifested in their perceived groups, differences, spatial levels, and the correlation with the livelihood of herdsmen [4-6]. Different to the herdsmen, local government managers play a dual role. They are not only the representatives of the local microcosmic subject, but also the practitioners of the national development strategy [7]. Their environmental perception is very important to solve the local ecological problem. LGMs, as executors of national policies and planners of regional development, directly affect herdsmen's livelihood and behavioral decision-making to a certain degree. Because local government managers' perceptions of ecological environment change are more clear, objective, and comprehensive than that of herdsmen. The influence of LGMs on regional ecological environment is more and more direct.

The GPP has been implemented for 15 years. How to timely adjust the grazing prohibition policy: Ban or lift? In order to analyze this problem, we conducted a case study on LGMs in the Yanchi County of Ningxia. Yanchi County is a typical ecological transition zone and desert grassland, which is located in the southwestern agro-pastoral ecotone of northern China. Grazing has been banned since November 2002. The land-use in Yanchi County is influenced by human activities and ecological policies, where the positive and negative processes of desertification are in contrast. With the process of the GPP, more problems abound and are outstanding, such as stall-feeding, trespass grazing, and the transformation of herdsmen's livelihood. This area is a typical example of a comprehensive analysis of the GPP. In view of the important role of the LGMs on ecological impact, this paper is based on the 16 LGMs in Yanchi County (party secretary, county magistrate, and the department head of economic, grassland, agriculture and environmental protection), on Grassland Ecological Perception Questionnaire survey data, and on the in-depth interview on the GPP evaluation. This paper discussed the ban or lift of the GPP from the change in the environmental perception of the LGMs (fundamental issue) and policy sustainability evaluation (key problem). The specific research ideas are shown in Figure 1. The innovations of this study includes the following aspects: (1) The perception measurement framework and indicators of the LGMs have been constructed based on the theory of a pratacultural system interface; (2) the prospects, exclusion, and duration of GPP and its internal restriction system have been analyzed based on the theory of a social-ecological system; (3) the symptom reflection of the GPP has been discussed from the deviation 
of a theoretical, hypothetical and implementation of the management system. Our analysis will provide a scientific basis for the timely adjustment of the GPP and point out the grassland management model in the agro-pastoral ecotone in the future.

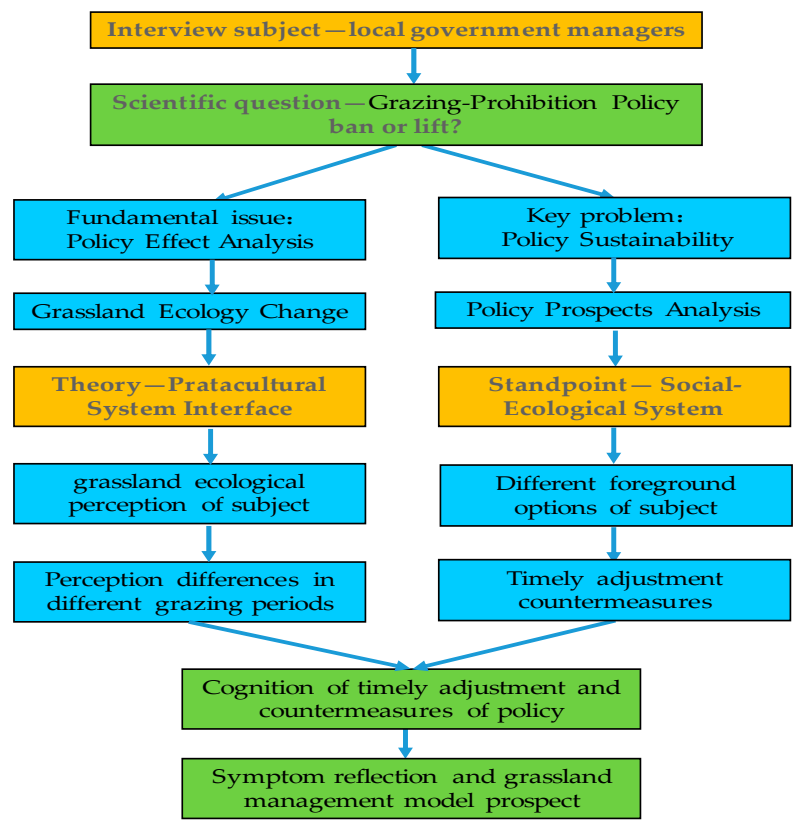

Figure 1. Ideas and methods of a timely adjustment of the grazing prohibition policy.

\section{Study Area}

Yanchi County $\left(37^{\circ} 04^{\prime} \mathrm{N}-38^{\circ} 10^{\prime} \mathrm{N}, 106^{\circ} 30^{\prime} \mathrm{E}-107^{\circ} 41^{\prime} \mathrm{E}\right)$ is located in the eastern part of the Ningxia Hui autonomous region of North Central China and is seated in the arid and semi-arid zone of the Ordos tableland transition to the Loess Plateau (Figure 2). The Mu Us Desert and the Loess Plateau lie to the north and south of Yanchi County, respectively [8]. Yanchi County, known as the Chinese hometown of Tan sheep and licorice, is an important ecological barrier of the Yellow River [9]. There are 101 villages with a total area of $8.67 \times 10^{5} \mathrm{hm}^{2}$, a cultivated land of $1.02 \times 10^{5} \mathrm{hm}^{2}$ and a grassland of $5.57 \times 10^{5} \mathrm{hm}^{2}$. It is a transition zone of climate, soil, and vegetation, which is also a typical transit region from agricultural production to pastoral areas.

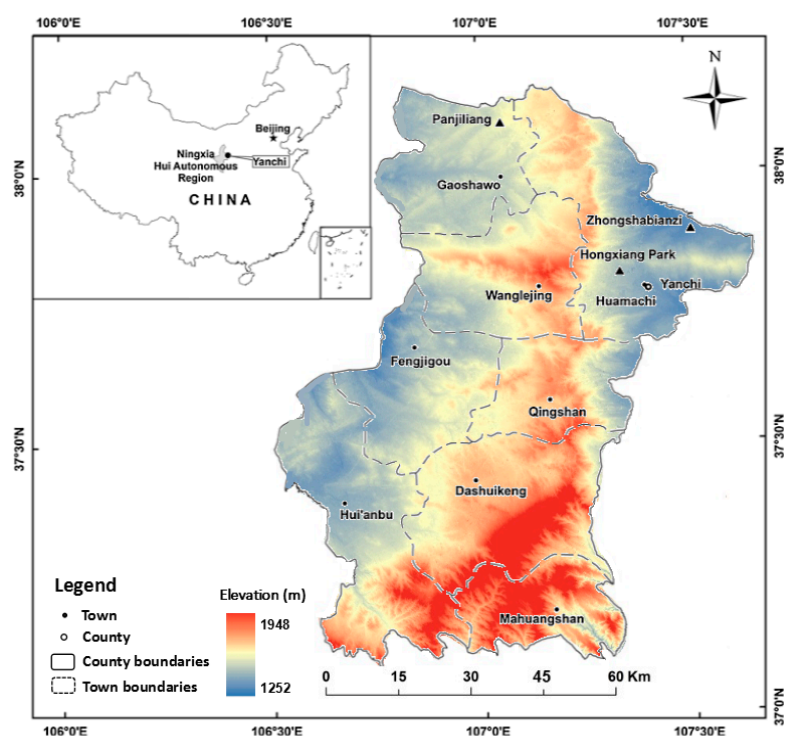

Figure 2. Location and administrative divisions of Yanchi County. 
Over the past 30 years, along with climate change, population explosion, overgrazing and over exploitation, Yanchi County grassland desertification has become a serious problem. The desertification area expanded from $1368.7 \mathrm{~km}^{2}$ in 1975 to $3509.80 \mathrm{~km}^{2}$ in 2000, accounting for $51.80 \%$ of the county area [10]. The GPP in Yanchi County was implemented on 1 November 2002 to cope with the expanding situation of desertification. Until 2014, the enclosure area of county grassland was $3.36 \times 10^{5} \mathrm{hm}^{2}$, the improved grassland by supplementary sowing was $1.34 \times 10^{5} \mathrm{hm}^{2}$. The GPP effectively improved the ecology of Yanchi County, and the trend of desertification reversal was very obvious, except for some grasslands in the northern desert. The desertification area decreased to $494.40 \mathrm{~km}^{2}$ in 2014 [11]. The grassland vegetation coverage increased from 30\% to 68\% in 2016.

\section{Methods and Data}

\subsection{Measurement of the Grassland Ecological Perception}

\subsubsection{Measurement Framework of the Grassland Ecological Perception}

The interface is a boundary and channel between the system and outside world. It is a link between different systems [12]. Spedding (1978) considered that there was an interface in the grassland ecosystem [13]. The characteristics of the grassland-animal interface were described in detail by Horn et al. (1987) [14]. Ren et al. (2000) defined the interface of the pratacultural system as the boundary of the ontological activities, that is, the composition of a system and its sequence [12]. They divided its structure into three interfaces: Grass-ground, grass-animal, and grass-human management, among which the grass-ground was the most basic interface in the pratacultural ecosystem (Figure 3). The coverage and abundance of the plant population are indicators to measure the health threshold and trend of the grassland system. However, there is a discordance between the temporal, spatial and inter-species systems in the grass-animal interface. The capacity and health level of the grassland system can be reflected by the index of the grassland safety utilization and critical storage. The grass-human management interface is a coupling system between the grass-animal system and human activities. It is the key to realizing the hierarchical management and sustainable development of the grassland ecosystem.

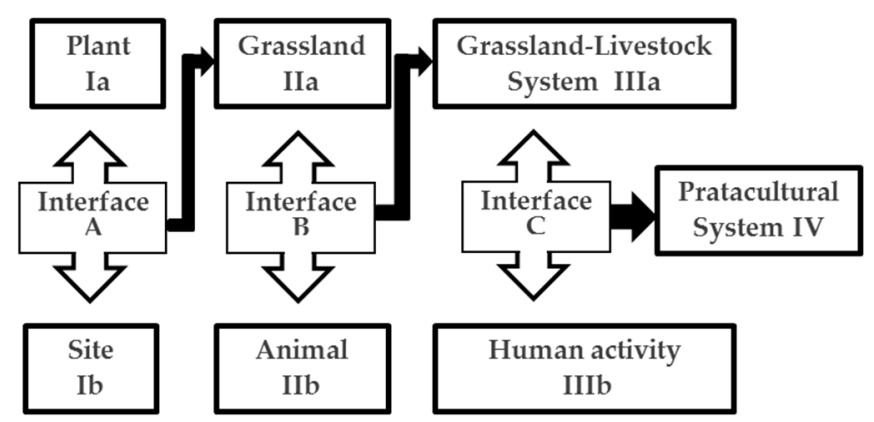

Figure 3. The theory of interfaces within a pratacultural system [12].

\subsubsection{Measurement Index System for the Grassland Ecological Perception}

The measurement framework of the grassland ecological perception of the LGMs was based on the pratacultural system interface. The grassland ecological, coverage, and species richness were selected to measure the change of the grass-ground interface. In terms of the index of the grassland quality, forage yield and livestock quantity were selected to reflect the change of the grass-animal interface based on the carrying capacity of grassland. Herdsmen are the most important production and decision-making unit, they are the subjects whose direct behavior affects the grassland. Their behavior, strategy, and lifestyle played a leading role in the evolution of the human-land system $[9,15]$. Therefore, the diversity of herdsmen's livelihood and the number of migrant workers 
can reflect the grass-human management interface. The specific measure index and assignment value are shown in Table 1.

Table 1. The measure index and assignment of the environmental perception.

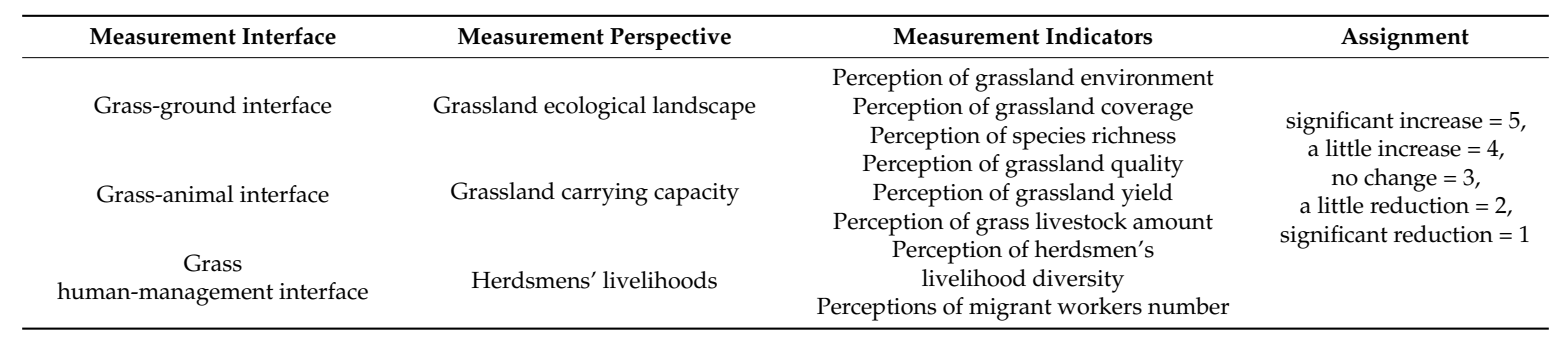

\subsubsection{Perceptual Quantitative Measurement and Difference Analysis}

First, the answers to the various measurements were assigned, and then the perception degree and relative perception intensity were calculated using Formulas (1) and (2).

$$
P I_{j}=\frac{\sum_{i=1}^{n} \sum_{o=1}^{m} L_{o v} L_{o n}}{\sum_{o=1}^{m} L_{o n}}
$$

where $P I_{j}$ is the LGMs perception degree index to $J$ problem, $L_{o v}$ is score of the $i$-th manager to $j$-view, $L_{o n}$ is number of the $i$-th manager for $J$ problem held an $o$ view, $m$ is the number of options for $J$ problem.

$$
R_{P I}=\frac{P I_{j}}{m} \times 100 \%
$$

where $R_{P I}$ is the relative perception intensity, and $P I_{J}$ is the perception degree of an LGM to $J$ problem, $m$ is the number of options for $J$ problem.

Second, the key time node was selected and the whole grazing prohibition period could be divided into the early stage (2003-2005), the intermediate stage (2006-2010) and the current stage (2011-2014) [16]. In order to probe the mechanism of the institutional factors' influence on desertification, the characteristics and laws of environmental perception were summarized, and the future policy development and countermeasures were considered. Hence, the difference analysis of the LGMs' grassland ecological perception was realized by frequency distributions and the Mann-Whitney $\mathrm{U}$ test. The Mann-Whitney $\mathrm{U}$ test was used to determine whether there is a statistically significant difference of the LGMs' grassland ecological perception between the two independent stages of the GPP.

\subsection{Data Sources}

In August 2016, field research on the achievement, problem, and optimization control of the GPP was carried out. This research was based on the consultation project of the Chinese Academy of Sciences, named "The agro-pastoral ecotone grassland utilization in northern China and grazing prohibition policy timely adjustment". The project group issued a questionnaire titled "Sustainable analysis of grassland utilization and ecological protection policy in Northern Agro-pastoral areas" at the seminar on 7 August 2016. The participants came from the Department of Science and Technology, Animal Husbandry, Forestry in the province of Ningxia Hui Autonomous and county government, Animal Husbandry and Development and Reform Commission of Yanchi County. A total of 20 questionnaires were distributed and 16 effective questionnaires were recovered. Details of the questionnaire are shown in Table 2. Although there were fewer questionnaires, the respondents were more representative and typical. 
Table 2. Details of the questionnaire.

\begin{tabular}{|c|c|c|}
\hline Survey Content & Number & Specific Content \\
\hline Social attribute information of the respondents & 8 & Name, sex, age, education, profession, unit, position, responsibilities \\
\hline Grassland ecological perception & 7 & $\begin{array}{l}\text { Grassland quality, coverage, forage yield, grass livestock amount, species richness, } \\
\text { degradation reasons }\end{array}$ \\
\hline $\begin{array}{l}\text { Evaluation of ecological compensation and } \\
\text { grazing-prohibition policy }\end{array}$ & 11 & $\begin{array}{l}\text { Compensation standard, trespass grazing, evaluation and regulation of } \\
\text { grazing-prohibition policy }\end{array}$ \\
\hline Evaluation the grassland management model & 5 & $\begin{array}{l}\text { The benefit score, advantages, disadvantages and problems of ecological migration, } \\
\text { grass on livestock, grazing-prohibition policy and grassland ecological protection } \\
\text { compensation }\end{array}$ \\
\hline
\end{tabular}

The project group visited the local Caragana-processing plant, the improved grassland in Langdonggou by air seeding, Tanyang Breeding Center, Ningxin Tanyang packinghouse, Heitukeng Tanyang farm, Medium degraded grassland and the Xiangyang village base of Soda grass. Furthermore, they consulted on the cost-benefit of Caragana processing and Tanyang breeding and noted the local herdsmen's attitude towards the GPP. During the job-site survey, the project team members conducted in-depth interviews with the questionnaire participants on the issues of "prohibition duration, existing problems, policy adjustment attitudes, and how to adjust". The following materials collected include the symposium report, grassland ecological data compilation of Yanchi County, and the field research expert report.

\section{Results and Analysis}

\subsection{Perceptions of the Grassland Ecological Changes of LGMs}

\subsubsection{Perceptions of the LGMs on the Grass-Ground Interface}

According to the doughnut chart of the LGMs perception in different GPP stages (Figure 4), $18.75 \%$ of the LGMs believed that the grassland coverage of Yanchi County had increased significantly after the GPP implementation. While, $43.75 \%$ of the LGMs preferred the view that the grassland ecology had a slight improvement before the GPP (Figure 4a). The fencing and grazing ban were beneficial to the survival and cluster of the main plant species. It could effectively improve the above ground biomass of the population. Therefore, $25 \%$ of the LGMs perceived a little improvement on species richness (Figure 4c). After a further period without grazing, grassland ecosystems in some areas had been restored. With the increase of rainfall, the ecological restoration was more effective than in early stages of the GPP. $43.75 \%$ of the LGMs believe the grassland ecological status of Yanchi County to be greatly improved in the intermediate stage of GPP (Figure 4a). In particular, the index of the grassland coverage and species richness selection rate of "minor improvement" increased from $25 \%, 25 \%$ in the early stage of GPP to $75 \%, 50 \%$ (Figure $4 \mathrm{~b}, \mathrm{c}$ ). At the current stage of GPP, the selection rate of the three indicators of "significant increase" on the grass-ground interface has increased significantly. However, after a longer period without grazing, new grassland ecological problems appeared-18.75\% of the LGMs perceived the degradation of grassland, $6.25 \%$ and $25 \%$ of the LGMs believed the grassland coverage and species richness to be decreased. Even $6.25 \%$ of LGMs perceived that species richness was significantly reduced. This conclusion is consistent with the conclusions obtained by Lu [17] and Wang [18] using MODIS NDVI products and sample surveys. There were related to the fixed number of years of GPP. 


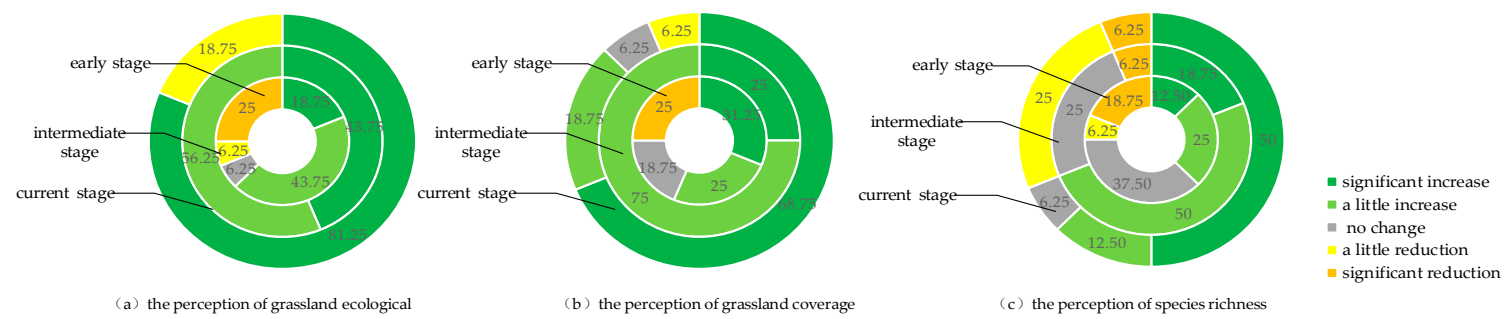

Figure 4. The local government managers (LGMs) perceptions on grass-ground interface in different grazing prohibition policy (GPP) periods. (a) indicate that the LGMs perception on grassland ecological. (b) indicate that the LGMs perception on grassland coverage. (c) indicate that the LGMs perception on species richness.

\subsubsection{Perceptions of the LGMs on the Grass-Animal Interface}

According to the doughnut chart of the LGMs perception (Figure $5 \mathrm{a}$ ), $31.25 \%$ of the LGMs believe that the grassland quality of Yanchi County has increased slightly after the GPP. After a further period without grazing, the grassland carrying capacity further improved. An increased number of LGMs perceived these changes of grassland quality as "a little increase" (68.75\%) in the intermediate stage of GPP to "greatly improved" (62.5\%) in the current stage (Figure 5a). Simultaneously, the LGMs perceived the selectivity of grassland yield as a "significant improvement" and increased from $37.5 \%$ in the early GPP to $43.75 \%$ in the mid-term and $56.25 \%$ in the current stage (Figure $5 \mathrm{~b}$ ). As a mandatory means, the GPP effectively inhibited herdsmen's over-grazing behavior, and slowed down the grassland desertification caused by the contradiction between forage yield and livestock demand for grass [8]. Thus, grassland ecology and vegetation were restored, and the carrying capacity was improved. It cannot be ignored that the grassland quality and forage yield declined in the current stage. The option selectivity of "a little reduction" of above index were $31.25 \%$ and $6.25 \%$, respectively (Figure 5a,b). These conclusions were basically the same with the change rule of the grass-ground interface.

According to the doughnut chart of the livestock amount (Figure $5 \mathrm{c}$ ), $35.71 \%$ of the LGMs believe that the number of sheep of Yanchi County had increased significantly after the GPP. In the absence of awareness and expectation for the GPP, herdsmen as rational brokers have generally increased the number of sheep under the incentives of government that encouraged pen feeding and gave a subsidy for sheds. According to the Lu et al. survey, the total amount of a sheep forage after 10 years of GPP increased by $60.7 \mathrm{~kg}$ compared with the early GPP period [19]. Due to the increase of the pen feeding cost, the herdsmen generally used night trespass grazing and obtained a semi-legalized status in the intermediate stage of GPP [20]. The health of herdsmen was greatly affected by the long-term night grazing, because this work was very intensive and risky. With the development of the county economy and the diversification of herdsmen livelihoods, $47.67 \%$ of the herdsmen adopted the shrinkage strategy of reducing the number of livestock [21]. About $50 \%$ of the retail breeding families cut back the livestock number [19], and the illegal grazing behavior decreased. According to the LGMs questionnaire, the selectivity of the regular ratio was $44 \%$, occasionally $48 \%$, and rarely $8 \%$ for the question "In current stage of GPP, the occurrence frequency of trespass grazing of herdsmen". The perception of the increase in the number of livestock dropped from $78.57 \%$ at the early stage, to $71.42 \%$ in the current stage of GPP. 


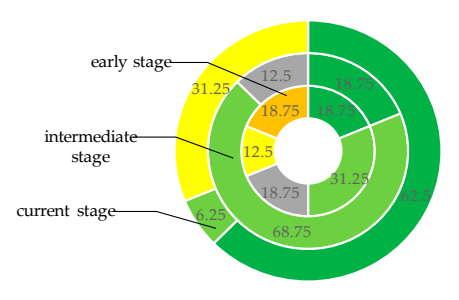

(a) the perception of grassland quality

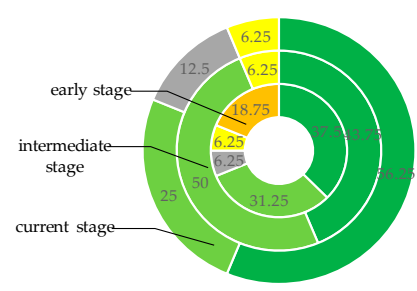

(b) the perception of grassland yield

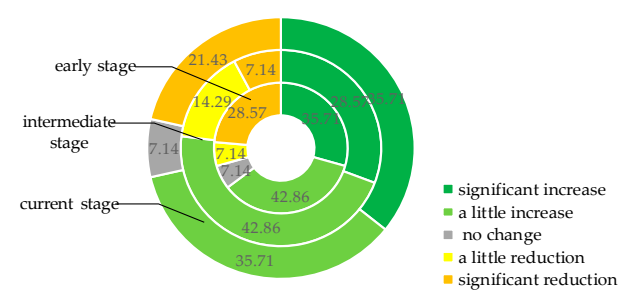

(c) the perception of grass livestock amount

Figure 5. The local government managers (LGMs) perceptions on the grass-animal interface in different grazing prohibition policy (GPP) periods. (a) indicate that the LGMs perception on grassland quality. (b) indicate that the LGMs perception on grassland yield. (c) indicate that the LGMs perception on grassland livestock amount.

\subsubsection{Perceptions of the LGMs on the Grass-Human Management Interface}

In the early stage of the GPP, the migrant workers number and the herdsmen's livelihood diversity showed an upward trend, with a selectivity of $62.5 \%$ and $25 \%$ (Figure 6). There were $31.25 \%$ (Figure 6a) and $56.25 \%$ (Figure $6 \mathrm{~b}$ ) of LGMs who said the two above aspects had not changed compared to the early stage. In general, the implementation of the GPP forced the herdsmen to adjust their traditional forms of livestock and planting structures and changed the flow of production materials and the allocation of labor resources. The number of rural migrant workers increased, but the diversity of livelihoods had not changed until the GPP was implemented. This is because the accumulation of the herdsmen's livelihood capital was not sufficient to support the productive investment in their non-agricultural livelihoods and the diversity of capital and labor. According to the Hou et al. survey in 2016, $48.67 \%$ of the herdsmen thought the cost of adapting to the GPP was relatively high [21], a large proportion of semi-herdsmen and non-farmers adopted the adjustment strategies of out-migrating for work [22]. At the current stage, the choice of out-migration for work, transportation, business and other non-farm livelihoods has increased by 37.14\% [19]. Among the 16 LGMs, the selectivity of "significant increase" of migrant workers number and herdsmen's livelihood diversity increased from $31.25 \%, 12.5 \%$ in the early stage to $37.5 \%, 18.75 \%$ in the intermediate stage and to $75 \%, 56.25 \%$ at current stage. The selectivity of "no change" reduced in every period.

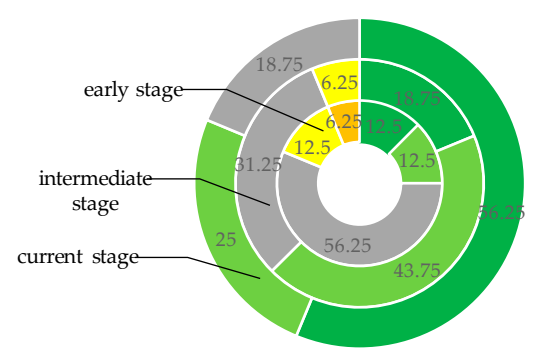

(a) the perception of herdsmen's livelihood diversity

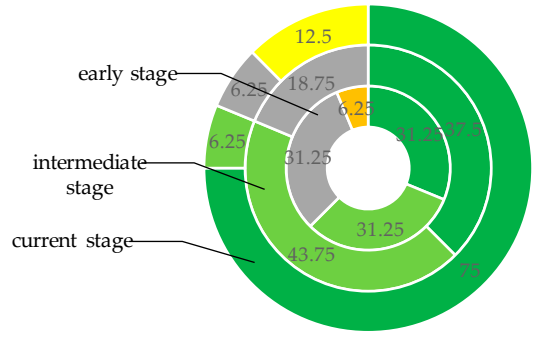

(b) the perception of migrant workers number
- significant increase

= a little increase

- no change

a little reduction
significant reduction

Figure 6. The local government managers (LGMs) perceptions on the grass-human management interface in different grazing prohibition policy (GPP) periods. (a) indicate that the LGMs perception on herdsmen's livelihood diversity. (b) indicate that the LGMs perception on migrant workers number.

\subsubsection{The Perception Degree and Difference of the LGMs in Different GPP Stages}

On the grass-ground interface, the perception of the LGMs was 3.875; the relative perception intensity was $77.5 \%$. Among which the perception of species richness was weakest (3.54), while the perception of grassland coverage and grassland ecological was relatively strong (Figure 7). The Mann-Whitney U test (Appendix A) showed that there were significant differences between the early and the last two stages of the GPP in grassland ecology and coverage, respectively $(p<0.021)$ (Tables A1 and A2). However, there were no statistically significant differences among the GPP periods 
in species richness $(p \geq 0.079)$ (Table A3). This demonstrated that the degraded grassland obviously recovered in the current stage. The constant changes of state space (grassland, livestock, human behavior) changed the grassland ecosystem from a mutually reinforcing process and structure to another steady state in the "ball-basin model". Thus, the recovery rate slowed down.

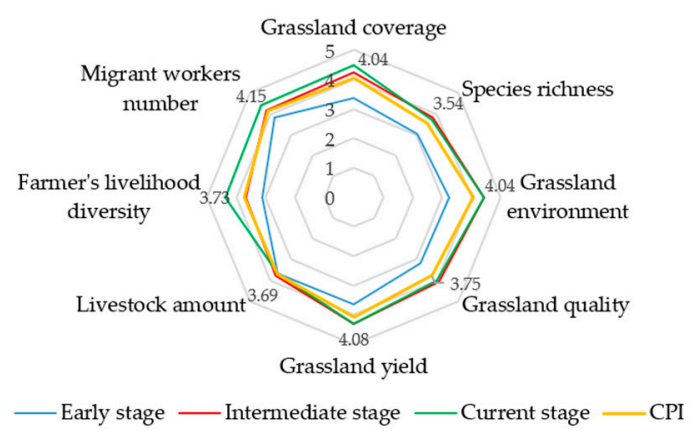

(a) Mean value of perception degree

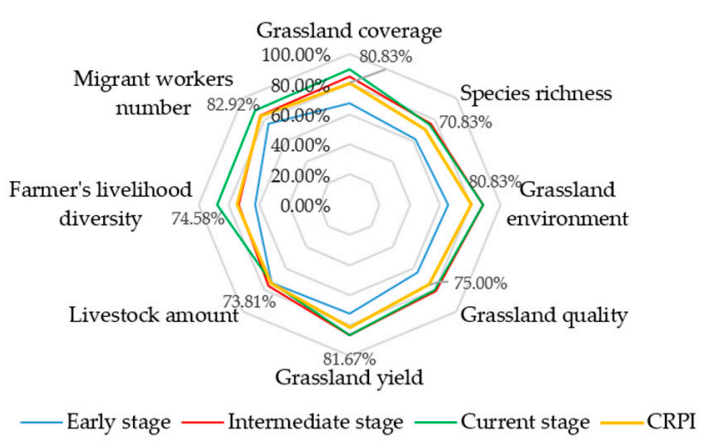

(b) Relative perception intensity

Figure 7. The radar chart of the local government managers (LGMs) perception degree and relative intensity. (a) indicate that the mean value of perception degree. (b) indicate that the relative perception intensity. The figures in the figure refers to the comprehensive value of $P I$ and $R_{P I}$ of each indicator. CPI is the comprehensive value of LGMs perception degree. $C R_{P I}$ is the comprehensive value of relative perception intensity.

On the grass-animal interface and the grass-human management interface, the perception of the LGMs was 3.841 and 3.938; the relative perception intensity was $76.83 \%$ and $78.75 \%$. Among which the perception of grassland yield was strongest (4.08), while the perception of the quality of grassland and the amount of livestock was relatively weak (3.69). The relative perception intensity of the diversity of the herdsmen's livelihood and number of migrant workers were $74.58 \%$ and $82.92 \%$ (Figure 7). No statistically significant difference was found among the GPP period in the grass-animal interface $(p \geq 0.061)$ (Tables A4-A6). However, there were significant differences between the current stage and the early stage in the grass-human management interface $(p<0.048)$ (Table A7). Furthermore, the index of herdsmen's livelihood diversity showed a significant difference between the current stage and the intermediate stage $(p<0.022)$ (Table A8). This demonstrated that the GPP had brought new opportunities for the transformation of herdsmen's ideology, occupation structure, employment orientation, employment space, income structure, and livelihood strategy. The herdsmen's livelihood and their diversity were rapidly increased in comparison with the early stage. This conclusion is consistent with the conclusions obtained by Lu et al. [19] and Hou et al. [21-23].

\subsection{Evaluation of Policy Sustainability Prospect of the LGMs}

\subsubsection{Effectiveness Evaluation and Prospect Forecast of the GPP}

Since the implementation of the GPP, land desertification in the agro-pastoral ecotone showed a significant reversal trend, and the desertification area decreased obviously. The questionnaire results of the LGMs for the effectiveness evaluation of the GPP showed that 56.25\% of the LGMs believed that the GPP in Yanchi County had achieved the expected effect in grassland vegetation cover and ecological restoration, but there were still $6.25 \%$ of the LGMs who believed the GPP had not achieved the desired results. The reason for this is that some areas have experienced some degree of degradation due to long-term grazing prohibition in the current stage.

If the GPP continued to be implemented, $50 \%$ of the LGMs thought it would improve the grassland ecology in Yanchi County in the future, but 25\% of the LGMs opposed it (Figure 8a). If the linkage between the arbitrariness factors was selectively and compulsorily severed by ecological policy, it would be difficult to achieve the expected results through a single, standardized and simplified, 
linear governance approach. It is reasonable to explain that in the early and middle stages of the GPP, due to the decrease of external disturbances, it had been obviously improved, but new problems have appeared at the current stage, to the extent that the grassland ecology has degraded.

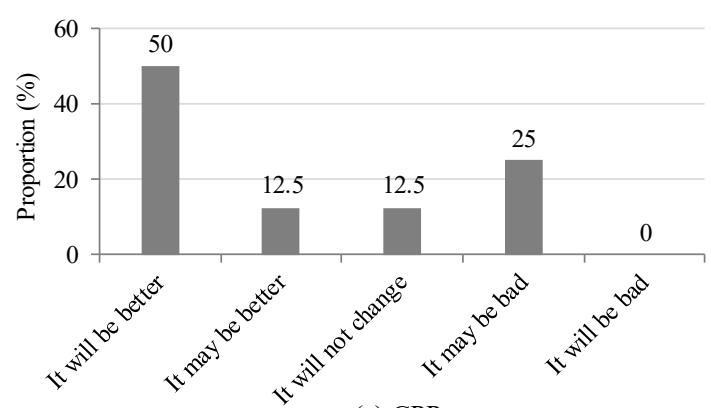

(a) GPP go

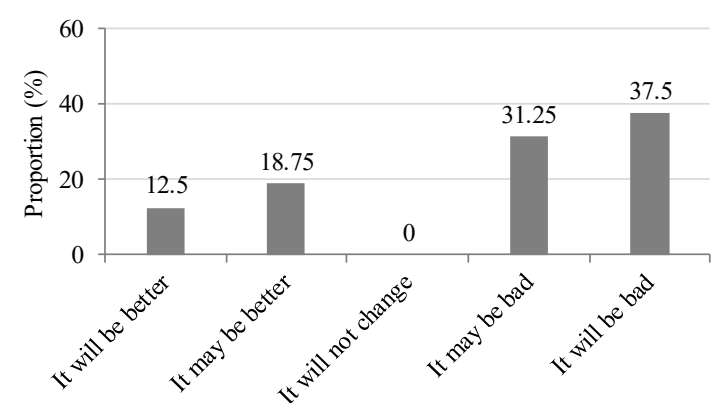

(b) GPP stop

Figure 8. Forecast of the relationship between the grazing prohibition policy (GPP) and grassland ecology. (a) indicate that If the GPP go, what will the local grassland ecology be like in the future? (b) indicate that If the GPP stop, what will the local grassland ecology be like in the future?

However, if the GPP stopped, 68.75\% of LGMs thought the grassland ecology would be worse, and the option of sure deterioration was $37.5 \%$ (Figure $8 \mathrm{~b}$ ). Since the GPP implementation, the number of herbivorous livestock in Yanchi County has increased from 410,321 in 2002 to 914,843 in 2011, more than double. The livestock density has increased from $68.24 / \mathrm{km}^{2}$ in 2003 to $117.29 / \mathrm{km}^{2}$. The number of herbivorous livestock is higher than 761,982, although it reduced obviously in the current stage of GPP. At present, the socio-ecological system of Yanchi grassland has not formed an effective governance mechanism to prevent the occurrence of a "tragedy of the commons". The sustainable alternative livelihoods of herdsmen and the rules of collective action and self-governance within the community, the social network, the supervision and the punishment mechanism are not mature. It is difficult to realize the goal of limiting livestock based on grassland carrying capacity caused by the imbalance of community resource endowment and the impact of economic benefits. If the GPP is lifted, the herdsmen would drive the sheep to grassland to reduce production costs against the background of the rising cost of pen feeding and the low eco-compensation. Hence, grassland ecology will face more severe challenges.

\subsubsection{Analysis of the Duration and Prescription of the GPP}

Is the longer the implement time of GPP, the more conducive to grassland recovery? Eighty-eight percent of the LGMs believed that excessive grazing destroyed the ecological balance of the grassland and did not conform to the natural laws of the grassland ecosystem virtuous circle. Grassland vegetation has a certain grazing tolerance and regeneration, which is influenced by precipitation. According to the "dynamic disequilibrium" theory, GPP, as the external disturbance of the social-ecological system, results in short-term temporal changes of the grassland carbon pool but has no effect on the long-term carbon dynamics of grassland [24]. Therefore, moderate grazing is beneficial to the benign cycle of grassland ecology. Grazing had been banned for a long time, the biodiversity and biomass of grassland had declined $[25,26]$ and the natural degradation gradually appeared. It is generally believed that five years was a suitable grazing ban period in Yanchi County, Ningxia $[27,28]$. For more than five years, the grassland should be moderately cultivated, mowed and seasonally grazed [29].

\subsection{Cognition of Timely Adjustment and Regulation Countermeasures of the GPP}

"Was there a need to adjust the GPP? How should it have been adjusted?" These two problems were the key issue to be solved urgently under the background of vigorously promoting the ecological civilization construction and green development. Among the 16 LGMs surveyed, three LGMs 
recommended the retention of the GPP, which is now completely banned in the whole county at all times (four seasons and $24 \mathrm{~h}$ ). Their main concern was that once the GPP was cancelled, grazing would be difficult to control, which would lead to the destruction of the ecological restoration of the GPP for many years. The remaining 13 LGMs considered it necessary to make appropriate adjustments to the current GPP. This selectivity accounted for as much as $81.25 \%$. They believed that the pure grazing prohibition was not in line with the local ecological background in the context of arid and semi-arid grassland, nor with the goal of the development of local animal husbandry, because the economic benefits of grazing prohibition were not significant.

The corresponding countermeasures had three aspects: First, grazing was the most cost-effective, the most efficient way of forage utilization. Moderate grazing utilization was beneficial to the circulation of grassland ecosystem regeneration. Some LGMs recommended an assessment of grassland ecological restoration in the subregion and an appropriate lifting of the ban according to the condition of vegetation restoration. A change in seasonal grazing could be implemented in order to achieve a reasonable balance between grassland and livestock. Furthermore, the local government encouraged planting an annual pasture.

Second, to create innovative institutional mechanisms, including grassland management, grassland ecological evaluation, and compensation standards of the GPP. "What traditional experiences in the past can be used for grassland management?" $25 \%$ of LGMs chose the first priority scheme to determine the livestock carrying capacity based on the grassland. It was considered an important measure to make a rational utilization of grassland resources and ensure the development of animal husbandry. The LGMs expect to increase the subsidies for this scheme. Ninety-six percent of the LGMs believed that the ecological compensation standard in Yanchi County was too low and $93.75 \%$ of LGMs expect the GPP to extend the subsidy period, increase the subsidy amount, and provide corresponding technical support (Figure 9a).

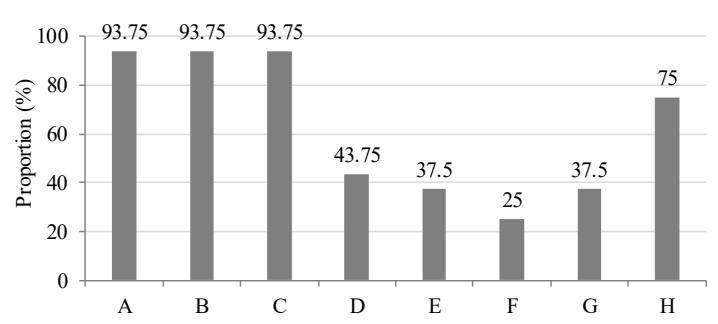

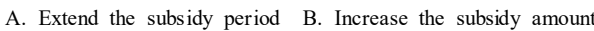
$\begin{array}{ll}\text { C. Provide technical support } & \text { D. Cultivate the market system }\end{array}$ E. Provide stable employment opportunities F. Provide loans
G. $\begin{array}{lll}\text { G. Develop social security } & H \text {. Introduce more Preferential policies }\end{array}$ (a) The expectations of ecological compensation of LGMs

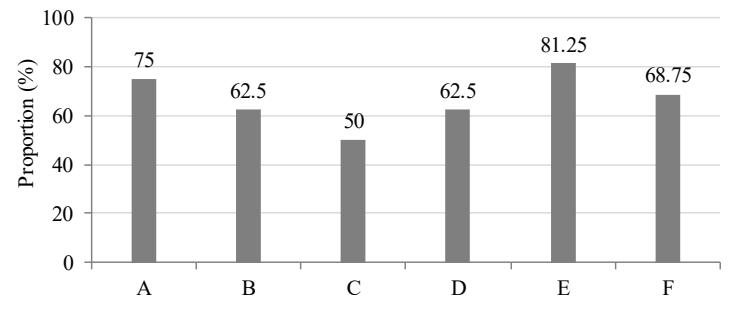

A. Improve ecological compensation standards B. Strengthen management supervision C. Strengthen publicity education D. Appropriate grazing E. Transform production methods F. Promote livelihoods diversification

(b) The solutions to the trespass grazing of LGMs

Figure 9. The expectations of ecological compensation and the solutions of the local government managers (LGMs) for trespass grazing. (a) indicate that the expectations of ecological compensation of LGMs. (b) indicate that the solutions to the trespass grazing of LGMs.

Third, more preferential policies should be introduced by local government to mobilize herdsmen's enthusiasm for ecological protection and to encourage the herdsmen to increase their income in a variety of ways and channels. Seventy-five percent of the LGMs held this view (Figure 9a). Through the multi-agent systems of herdsman-government behavior, Liu et al. found that the illegal grazing behavior of herdsman could be decreased when the ratio between the number of inspectors and herdsman reached 1.5, or the ratio between the forfeit and income of trespass grazing reached 5.8, or the probability of trespass grazing being detected was greater than 0.73 [30]. The transformation of the herdsmen's mode of production and the non-agricultural and diversified livelihood of herdsmen can fundamentally and effectively put an end to the phenomenon of illegal grazing at night [30,31]. The option support rates for the LGMs were $81.25 \%$ and $68.75 \%$, respectively (Figure $9 \mathrm{~b}$ ). 


\section{Discussion}

\subsection{Reflection on the Policy of Grazing Prohibition}

5.1.1. Theoretical Deviation in Management System: Equilibrium System Theory and Neglected System Integrity

Based on the above analysis, the government-oriented approach was the main mode of desertification control in Yanchi County. The idea of governance was based on the theory of equilibrium system. In terms of the GPP, $56.25 \%$ of the LGMs attributed desertification in Yanchi County to overgrazing. They thought that only by strictly controlling livestock population and grazing behavior could they eliminate the human activities that interfere with the grassland, and the desertification areas could recover through self-regulation [32]. In terms of external disturbances (climate change), the LGMs believe that by building sheds, rearing, introducing or improving livestock varieties and artificial grass, the shortage of forage caused by insufficient rainfall or disasters could be solved. The GPP is based on equilibrium system theory which ignores the entirety and complexity of the social-ecological system and separates the interrelation between the elements in the ecosystem. The above causes led to the obvious improvement of grassland in the primary and mid-term stages due to the decrease of external disturbance. At the current stage, however, this was counterproductive. This reality was consistent with Scott's theory of "scientific forestry utopia" (2004) in the "national perspective" [33].

\subsubsection{Hypothetical Deviation in the Management System: Profit-Driven and Disruptive Herdsmen}

The managers regarded the livestock as herdsmen's production and husbandry as profit means. From the view of policy design of the equilibrium system theory, they thought that herdsmen were the profit-driven group in modern market economy. However, the herdsmen chose subsistence husbandry, which pursues the production target of satisfying their own livelihood demand and maintaining the life attitude of a balanced utilization of resources before the market economy entered the pastoral area. The traditional cultural husbandry habit and ecological wisdom and value system formed over a long time deeply influenced herdsmen's production decision-making and the resource utilization attitude. After the nature was "capitalized", the grassland and livestock were treated as capital endowed with abstract market prices. The herdsmen were also labeled mercenaries. The social-ecological giant system of agro-pastoral ecotone as a whole was severed. When the links between institutional elements were eliminated and traditional husbandry were broken, the grassland became a kind of "contradictory dwelling" (the contradiction between closed and coupled system openness of grassland production system [12,15], the contradiction between livestock demand and forage yield, the contradiction between herdsmen's short-term economic benefits and long-term ecological benefits). Previous researches were based on the identity of the "rational economic man" of herdsmen, which regarded herdsmen as the environment destroyers, ignoring their sensitive observation of environment in the past nomadic process, mutual aid mechanism and collective protection.

5.1.3. Deviations in the Implementation of the Management System: Trade-Off between Ecological Benefits and Economic Benefits

Yanchi County is a typical agro-pastoral area, agriculture was the main way to solve the problem of population, food and forage shortage for herdsmen. Husbandry was a means of increasing income and the most important livelihood of local herdsmen. The implementation of the GPP resulted in changes in production and labor. The most economical and least costly grazing methods were restricted. The traditional way (livestock movement) of avoiding the risk of external uncertainty was difficult to carry out after the implementation of grassland contracting and fencing. The herdsmen were only to resist disasters through the establishment of sheds and foraging. As a result, their culturing cost increased, and income declined. Many herdsmen began grazing without permission at night to reduce 
their costs. The contradiction between the herdsmen's short-term economic benefit and long-term ecological benefit was outstanding. This contradiction also manifested in the management process of local government. From the perspective of the LGMs, husbandry was the pillar industry of the county's economic development. The significance and value of regional GDP growth was much higher than the ecological benefit in the evaluation system of local government. Under the requirement of economic development and ecological benefit, the Yanchi government was confronted with the high cost of grassland supervision and high intensity task. The LGMs had a contradictory attitude towards the GPP. When the GPP became a routine activity, the department of grass-roots government adopted a flexible treatment method in the prohibition time, space category, the trespass grazing behavior and punishment standard.

\subsection{Prospect of Grassland Management Model in the Agro-Pastoral Ecotone}

According to the 2017 report of the Food and Agriculture organization of the United Nations on the global food crises, 108 million people faced serious food security problems in 2016 [34]. With the progress of human technology and the adjustment of dietary structure (the growing demand for meat), biofuels and livestock consumed half of the global grain. Therefore, mankind would be confronted with a new form of grain "famine". Grassland ecosystem was an open system. If it was artificially delineated as a closed-systems, and the entry of an external negative entropy flow was restricted, it would be unfavorable to the cycle renewal and restoration of grassland ecology. In a word, based on the above social and ecological background, the GPP urgently need to adjust the management mode, time limitation, and space category according to the vegetation restoration.

Hou et al. selected 2003-2015 as the reference period and used the system dynamics model to simulate the possible scenarios of grassland social-ecological systems under different ecological compensation standards in the next decade. This result showed that the GPP significantly promoted the resilience of social-ecological system. With the improvement of the compensation standard, the grassland society system became more stable, but the ecosystem resilience decreased. The compensation standard of $\$ 17.31$ / ha was relatively reasonable, which had the best effect on promoting the restoration of grassland social-ecosystem in the following 10 years [23]. This conclusion differed from the willingness of the LGMs who recommend higher compensation standards. The eco-compensation had nothing to do with the herdsmen's behavior and the effect of grassland protection. Therefore, the protection of grassland ecology can not only rely on the government's considerable eco-compensation, but we need to explore a more reasonable and feasible grassland management system.

Is it feasible that the GPP be lifted? What will happen if the GPP stops? The survey of grazing experiments conducted by Yang et al. in Dashuikeng Town in 2012 can answer the above question. This town, as the integrated pilot scheme for animal load balancing and rangeland management, implemented the grazing trial (limiting livestock based on grassland carrying capacity and seasonal grazing) in 2006. This trial covered 4146 herdsmen and $6.37 \times 10^{4}$ ha land. After grazing, the whole farming scale decreased, and the difference of the grazing scale between herdsmen increased. The grazing time was shorter than the traditional free grazing. Sixty percent of the herdsmen who participated in the trial adopted the combination of pen feeding and free-grazing. The overloading phenomenon was significantly reduced, and the net income of sheep increased by $18.9 \%$. After two years of the experiment, $48.3 \%$ of the herdsmen thought that the quality of herbage after grazing was better. At the same time, the right to the grassland contract management began to flow [35]. The pilot scheme restored the use of grazing land rights, and enhanced community participation and autonomy. It provided new ideas and experiences for the solution to the rangeland management and the dilemma of GPP. The conclusions of the grazing experiment for grassland management are: (1) Policy makers should focus on both the rangeland conservation and herdsmen's livelihoods; (2) flexible management plans and community participation mechanism, including property rights system, collective selection rules, trust and moral growth, and supervision punishment, 
should be developed. Therefore, the individual commitment and community management should be introduced to the market system, rather than simply the supervision and eco-compensation from governments [35]. In conclusion, the appropriate adjustment of the GPP by local authorities is correct and has a certain rationality and adaptability. However, through an in-depth analysis of a series of regulatory policies, it was found that the basis of these policies was still the linear solution of equilibrium theory. Its perspective was still mostly limited in the operational level of government policy and system reform. These measures did not pay attention to the effect of market, laws, communities and informal institutions. The government should break the fence boundary, support grassland sharing and mobile grazing between herdsmen and encourage the collective action and self-management between communities. It is necessary to end the situation that shares the profits only in the circulation field, while herdsmen alone bear the risk and losses in the purchase and sale system of animal products in China. Hence, the central government should implement the tax system of ecological management. The consumers who buy the livestock products should pay the cost of ecological construction. Based on the non-equilibrium theory and polycentric governance, the multi-central grassland governance and control system should be built, which should include government intervention, market regulation, enterprises, experts and scholars, various organizations and the participation of herdsmen from a social-ecological holistic perspective.

\section{Conclusions}

Public perception of environmental change was an important entry point for the study of the man-land relationship in recent years. The research results on herdsmen's perception of environmental change in ecologically fragile areas (Gannan Plateau, Yellow River source areas, agro-pastoral ecotone and inland river basin) were quite abundant. As an important driving force to influence environmental change, the analysis of the LGMs' perception was helpful to understand regional environmental change more comprehensively and objectively, and to reveal the key factors of ecological restoration. The corresponding control measures were also put forward. Thus, the study of the LGMs' perspective on environmental change had strong analytical value and guiding significance. The GPP was one of the most important ecological protection policies in the agro-pastoral zone of northern China. In the course of more than 10 years' implementation, the desertification of land showed a clear reversal trend. Based on the perspective of LGMs, this study analyzed the characteristics and related factors of grassland ecology in different stages of the GPP, which provided the basis for the development of the GPP and the corresponding regulatory measures. The conclusions were as follows:

Local government managers had a strong perception of grassland ecological change. The comprehensive perception index and its perceived intensity were higher than 3.8 and $76 \%$ respectively. The results of the LGMs perception were basically consistent with the objective facts. The grassland ecology, coverage, quality, yield, and species richness in Yanchi County performed with obvious regularity, there was an improvement in the early GPP period, an obvious improvement in the intermediate stage and a significant improvement with some degradation in the current stage. The reasons for the above regulation were related to the fixed number of years of prohibition. The longer the grazing prohibition time was, the more disadvantageous the grassland restoration had.

The GPP in Yanchi County basically achieved the expected effect of grassland vegetation cover and ecological restoration. Therefore, the GPP should continue to be implemented on the basis of appropriate adjustments by the local government. The adjustment ideas were as follows: (1) To determine the livestock carrying capacity according to the grass and adjust the seasonal grazing.

(2) To improve the standard of compensation for grass and livestock balance. (3) To bolster the diversification of herdsmen's livelihoods and non-agriculturalization.

The model of grassland governance in Yanchi County must go beyond the era of restricting human activities solely on the mandatory policy from the social-ecological system integrity perspective. Based on the non-equilibrium theory and polycentric governance, the multi-center grassland 
governance and control system should be built and should include government intervention, market regulation, enterprises, experts and scholars, various organizations and the participation of herdsmen.

Author Contributions: L.Z. and Y.W. conceived the general idea of this paper and conducted the interviews. The first and final drafts were written by L.Z. in collaboration with Y.W. The materials and analysis tools were prepared by Y.W including to the figures and tables. G.Y. designed the research methodology and supervision. All authors analysed and discussed the results.

Funding: This paper was financially supported by the National Key Research and Development Program of China [No.2018YFA0606402, No.2016YFC0500909], the National Natural Science Foundation of China [No. 41471436], [No. 41807519], [No.41601587], and the Key Laboratory of Desert and Desertification Open Fund of Northwest Institute of Eco-Environment and Resources, Chinese Academy of Science [KLDD-2018-002].

Conflicts of Interest: The authors declare no conflict of interest.

\section{Abbreviations}

The following abbreviations are used in this manuscript:

$\begin{array}{ll}\text { GPP } & \text { Grazing-Prohibition Policy } \\ \text { LGMs } & \text { Local Government Managers } \\ \text { SES } & \text { Social-Ecological System }\end{array}$

\section{Appendix A}

Table A1. Mann-Whitney U Test of the grassland ecological landscape on the grass-ground interface.

\begin{tabular}{cccc}
\hline Asymp. Sig. (Two-Tailed) & Early Stage & Intermediate Stage & Current Stage \\
\hline Early stage & - & $0.015^{*}$ & $0.003^{* *}$ \\
Intermediate stage & & - & 0.129 \\
Current stage & & - \\
\hline \multicolumn{2}{c}{ and ${ }^{* *}$ are significant at $p<0.05$ and $p<0.01$, respectively. }
\end{tabular}

Table A2. Mann-Whitney U Test of the grassland coverage on the grass-ground interface.

\begin{tabular}{cccc}
\hline Asymp. Sig. (Two-Tailed) & Early Stage & Intermediate Stage & Current Stage \\
\hline Early stage & - & $0.014^{*}$ & $0.021^{*}$ \\
Intermediate stage & & - & 0.063 \\
Current stage & & & - \\
\hline
\end{tabular}

${ }^{*}$ is significant at $p<0.05$.

Table A3. Mann-Whitney U Test of the species richness on the grass-ground interface.

\begin{tabular}{cccc}
\hline Asymp. Sig. (Two-Tailed) & Early Stage & Intermediate Stage & Current Stage \\
\hline Early stage & - & 0.079 & 0.136 \\
Intermediate stage & - & - & 0.666 \\
Current stage & & - \\
\hline
\end{tabular}

Table A4. Mann-Whitney U Test of the grassland quality on the grass-animal interface.

\begin{tabular}{cccc}
\hline Asymp. Sig. (Two-Tailed) & Early Stage & Intermediate Stage & Current Stage \\
\hline Early stage & - & 0.074 & 0.061 \\
Intermediate stage & - & & 0.074 \\
Current stage & & - \\
\hline
\end{tabular}

Table A5. Mann-Whitney U Test of the grassland yield on the grass-animal interface.

\begin{tabular}{cccc}
\hline Asymp. Sig. (Two-Tailed) & Early Stage & Intermediate Stage & Current Stage \\
\hline Early stage & - & 0.283 & 0.204 \\
Intermediate stage & - & - & 0.283 \\
Current stage & & - \\
\hline
\end{tabular}


Table A6. Mann-Whitney U Test of the grass livestock amount on the grass-animal interface.

\begin{tabular}{cccc}
\hline Asymp. Sig. (Two-Tailed) & Early Stage & Intermediate Stage & Current Stage \\
\hline Early stage & - & 0.806 & 0.865 \\
Intermediate stage & - & & 0.961 \\
Current stage & & - \\
\hline
\end{tabular}

Table A7. Mann-Whitney U Test of herdsmen's livelihood diversity on grass-human management interface.

\begin{tabular}{cccc}
\hline Asymp. Sig. (Two-Tailed) & Early Stage & Intermediate Stage & Current Stage \\
\hline Early stage & - & 0.068 & $0.001^{* *}$ \\
Intermediate stage & & - & $0.022^{*}$ \\
Current stage & & - \\
\hline \multicolumn{2}{c}{${ }^{*}$ and ${ }^{* *}$ are significant at $p<0.05$ and $p<0.01$, respectively. }
\end{tabular}

Table A8. Mann-Whitney U Test of migrant workers number on grass-human management interface.

\begin{tabular}{cccc}
\hline Asymp. Sig. (Two-Tailed) & Early Stage & Intermediate Stage & Current Stage \\
\hline Early stage & - & 0.359 & $0.048^{*}$ \\
Intermediate stage & - & & 0.130 \\
Current stage & & - \\
\hline
\end{tabular}

$*$ is significant at $p<0.05$.

\section{References}

1. Wang, F.T.; An, P.L.; Cai, L.J.; Huang, X.X.; Hao, J.M. Monitoring effects of ecosystem restructuring project for returning grain plots to forestry in Wuchuan county of Inner Mongolia based on RS and GIS. Trans. Chin. Soc. Agric. Eng. 2015, 31, 269-277. (In Chinese)

2. Xu, J.Y.; Liu, W.H.; Chen, J.; Ma, L. Exploring strategies about ecological improvement based on local responses in northern agro-pastoral ecotone. Acta Ecol. Sin. 2010, 30, 6126-6134. (In Chinese)

3. Tong, G.F. On Legal mechanism of grassland PES in China. J. Nanjing Univ. Technol. (Soc. Sci. Ed.) 2015, 14, 47-53.

4. Zhao, X.Y. Environmental perception of herdsmens of different livelihood strategies: A case of Gannan Plateau. Acta Ecol. Sin. 2012, 32, 6776-6787. [CrossRef]

5. Chen, Y.; Zhou, L.H. Herdsmens' perception of the decade-long grazing ban policy in Northern China: A case study of Yanchi County. Sustainability 2016, 8, 1113. [CrossRef]

6. Engdawork, A.; Bork, H.R. Herdsmens' perception of land degradation and traditional knowledge in southern Ethiopia-resilience and stability. Land Deegrad. Dev. 2016, 27, 1552-1561.

7. Qin, H.B.; Li, Y.M.; Liang, L.H. Evaluation of China's grassland conservation work during the period of the 11th five-year plan. China Soft Sci. 2013, 12, 61-65. (In Chinese)

8. Liu, N.; Zhou, L.H.; Hauger, J.S. How sustainable is government-sponsored desertification rehabilitation in China? Behavior of households to changes in environmental policies. PLoS ONE 2013, 10, 1-8. [CrossRef]

9. Wang, Y.; Zhou, L.H.; Chen, Y.; Lu, H.L.; Wei, X. Relationship between the herdsmens' livelihood capital and the desertification reversion trend: A case study in Yanchi County, Ningxia. Acta Ecol. Sin. 2017, 37, 2080-2092. (In Chinese)

10. Ma, Y.H.; Zhou, L.H.; Zhu, Y.L.; Li, B. Time series variation in the driving factors leading to land desertification in Yanchi County over the last 50 year. Arid Zone Res. 2009, 26, 249-254. (In Chinese) [CrossRef]

11. Ma, M.D.; Xie, Y.Z.; Mi, W.B.; Liu, C.N.; Ma, T.; Ao, H.W. Land use and land cover change of the sand drift areas in eastern Ningxia and its response to ecology: A case of Yanchi County. J. Arid Land Resour. Environ. 2014, 28, 8-14. (In Chinese)

12. Ren, J.Z.; Nan, Z.B.; Hao, D.Y. The three major interfaces within pratacultural system. Acta Pratacult. Sin. 2000, 9, 1-8. (In Chinese)

13. Spedding, W.C.R. The Introduction Grassland Introduction; Cambridge Press: London, UK, 1987. 
14. Horn, F.; Hodson, J.; Mot, J.; Brougham, R. Grazing-Land Research at Plant-Animal Interface; USAD office of International Cooperation and Development and USDA Agricultural Research Service; Winrock International: Little Rock, AR, USA, 1987. Available online: https:/ / publications.csiro.au/rpr/pub? list=BRO\&pid=procite:0a951a21-8def-4bda-a7ba-9f532f447d66 (accessed on 18 December 2018).

15. Zhang, W. Grassland ecological programs in the context of environmentalism-An anthropological reflection. China Agric. Univ. J. Soc. Sci. Edi. 2013, 30, 111-122.

16. Wang, Y.; Zhou, L.H. Assessment of the coordination ability of sustainable social-ecological systems development based on a set pari analysis: A case study in Yanchi County. Sustainability 2016, 8, 733. [CrossRef]

17. Lu, H.L. Evaluation of Economic and Ecological Effects and Sustainability of Grazing Prohibition Policy in farming-Pastoral Transition Zone: A Case of Yanchi County, China. Ph.D. Dissertation, Chinese Academy of Sciences University, Beijing, China, 2016; p. 24.

18. Wang, G.Q.; Zhang, K.B.; Wang, Z.S. Desert grassland ecosystem health evaluation under different fenced enclosure conditions. Sci. Soil Water Conserv. 2014, 12, 40-46. (In Chinese)

19. Lu, H.L.; Zhou, L.H.; Chen, Y.; Ma, B.; Wei, X. Adaptive strategy of peasant households and its influencing factors under the grazing prohibition policy in yanchi county, ningxia hui autonomous region. Acta Ecol. Sin. 2016, 36, 5601-5610.

20. Chai, H.F.; Li, Q.X.; Fu, R.; Zuo, T. The evolution and imply of prohibiting grazing policy deadlock: Based on the observation of Yanchi rural. Agric. Econ. 2009, 1, 93-98. (In Chinese)

21. Hou, C.X.; Zhou, L.H.; Wen, Y.; Chen, Y. Herdsmens' adaptability to the prohibiting grazing policy from the perspective of social-ecological system: A case study in yanchi, ningxia, China. J. Desert Res. 2018, 38, 872-880.

22. Hou, C.X.; Zhou, L.H.; Wen, Y.; Chen, Y. Farmers' adaptability to the policy of ecological protection in China-A case study in Yanchi County, China. Soc. Sci. J. 2018, 55, 404-412. [CrossRef]

23. Hou, C.X.; Zhou, L.H.; Wen, Y.; Chen, Y. Evaluation of social-ecological systems resilience in ecological policy. China Popul. Resour. Environ. 2018, 28, 117-126.

24. Luo, Q.P.; Gong, J.R.; Zhai, Z.W.; Pan, Y.; Liu, M.; Xu, S.; Wang, Y.H.; Yang, L.L.; Baoyin, T.T. The responses of soil respiration to nitrogen addition in a temperate grassland in northern China. Sci. Total Environ. 2016, 569, 1466-1477. [CrossRef]

25. Nishizawa, K.; Tatsumi, S.; Kitagawa, R.; Mori, A.S. Deer herbivory affects the functional diversity of forest floor plants via changes in competition-mediated assembly rules. Ecol. Res. 2016, 31, 569-578. [CrossRef]

26. Jing, Z.B.; Cheng, J.M.; Chen, A. Assessment of vegetative ecological characteristics and the succession process during three decades of grazing exclusion in a continental steppe grassland. Ecol. Eng. 2013, 57, 162-169. [CrossRef]

27. Liu, X.D.; Zhang, K.B.; Wang, X.; Ma, F.J. Influence of enclosure ages on community structure and species diversity of sandy grassland. Bull. Soil Water Conserv. 2015, 35, 39-43. (In Chinese)

28. Pang, J.L.; Zhang, K.B.; Wang, H.X.; Wang, L.L.; Su, P.F.; Wang, X. Effects of artificial enclosure on vegetation composition and plant diversity in arid and semi-arid region: Yanchi County, Ningxia as an example. J. Northeast For. Univ. 2013, 41, 40-43. (In Chinese)

29. Li, W.; Liu, Y.Z.; Wang, J.L.; Shi, S.L.; Cao, W.X. Six years of grazing exclusion is the optimum duration in the alpine meadow-steppe of the northeastern Qinghai-Tibetan Plateau. Sci. Rep. 2018, 8, 17269. [CrossRef]

30. Liu, M.Y.; Tang, Y. The simulation of illegal grazing with multi-agent systems. China Popul. Resour. Environ. 2018, 28, 198-201. (In Chinese)

31. Tang, Y.; Liu, M.Y. The game analysis of illegal grazing and its corresponding countermeasures. Acta Agrestia Sin. 2018, 26, 1146-1149. (In Chinese)

32. Cui, W.C. Application of theory of dissipative structure in reversion process of derstification. Arid Land Geogr. 2003, 26, 150-153. (In Chinese)

33. Scott, J.C. Seeing Like a State: How Certain Schemes to Improve the Human Condition Have Failed; Yale University Press: New Haven, CT, USA, 1998. 
34. FAO. Global Report on Food Crisis 2017. 2017. Available online: http:/ /www.fao.org/emergencies/resources/ documents/resources-detail/en/c/876564/ (accessed on 18 December 2018).

35. Yang, R.L.; Qi, G.B.; Zuo, T. An exploratory study on the utilization and management of rangeland in farming-pastoral ecotone after the grazing-ban policy: Based on the field study on planned-grazing pilot in Ningxia. China Popul. Resour. Environ. 2014, 24, 118-125. (In Chinese) 